\title{
THE REGENERATION OF CUT-OVER AREAS ${ }^{1}$ BY R. C. HOSIE2
}

In any natural forest a given species attains its dominant position because of some special adaptation that gives it enough advantage over its competitors to assure its survival.

That simply means, that at some time during the life span of the species, conditions will arise that are particularly suitable for its regeneration, while being at the same time, less favorable, or not at all suitable for the regeneration of its competitors.

When such conditions occur, that species has a great advantage over all others. It becomes established and, barring accident, goes on to form a renewed part of the forest.

In the pulpwood region there are several tree species competing with one another for a place in the forest. In this province (Manitoba) and throughout most of Canada these are: black spruce, white spruce, balsam, jack pine, poplar and white birch.

Throughout the length and breadth of the area, in which these six species grow, conditions differ from place to place. In one part, at a given time, they may favor the reproduction of white spruce, in another part that of balsam, in still another that of jack pine, or it may be poplar that is favored, or birch, or a mixture of the species.

Conditions also differ in time. Over long periods they may be unfavorable in one place for the reproduction of any species-then, suddenly, during a short period, they may favor the reproduction of one of the six and if that species is there at the time and able to take advantage of the opportunity it goes on to renew that part of the forest.

As a result of these differences - differences from place to place, differences in any one place from time to time, and differnces in the reproductive habits of the species - we have a varied forest composition. Over large areas black spruce predominates and in other parts it is jack pine. Extensive areas are dominated by poplar, or white birch, or a mixture of the two. Large areas are mainly balsam, or balsam with scattered spruce and white birch, or other combinations of the species may occur.

We refer to these different aspects of the forest as types, or stands and it is largely accidental that they occur in their present situations. Had conditions been different at the time when the black spruce stand that we are cutting today began its career, we could have had instead of poplar stand, or a jack pine stand, or a mixedwood forest. But at that time, black spruce was given the right conditions and the others were not. If they were, then they hadn't the seed or the means to take advantage of the opportunity.

Thus, we see, that it isn't just enough that the trees bear seed, some of them such an abundance of it that one crop would be cnough to repopulate all the cut-over and burned-over land in Canada. Year after year the poplar, for example, sheds millions of tiny little sceds, each provided with a tuft of down. These seeds can be carried far by the wind and scattered over the cut-

\footnotetext{
1 A Paper prepared for the 1953 Annual Meeting of C.I.F. at Winnipeg.
}

2 Professor of Forestry. Univergity of Toronto. 
over areas and over the burns and in the uncut forest. But is the poplar that grows on some of our burns and on many of our cut-over areas from seed? Generally speaking it is not-usually it is from the roots of poplars that were killed by the burning, or cut in the logging.

It is still not enough that the conditions are favorable for seed germination and the establishment of seedlings. During such time, seed may not be available. Jack pine, for example, holds its seed for years in tightly closed cones. White spruce is not an annual seeder. Black spruce retains most of its seed, shedding only a little at a time and only under very favorable circumstances. Insects, birds and rodents use seed as food. Fungi, unfavorable weather and other agencies destroy great quantities of it. Thus there are times when there is none available for the production of seedlings.

There are then two requirements-seed and a favorable seedbed, or the equivalent of these. That means, first, that a living part of the tree must be present. For some species like white spruce and jack pine that is seed. For others like poplar, birch, black spruce or balsam, seed is not always necessary since these can reproduce from living roots or branches. Second, the place nust be favorable for the establishment of the species. For those, like white spruce, that reproduce only by seed, that means a good seedbed with usually some protection for the seedlings when they arise. For those that can reproduce without seed, like poplar, all that is required are favorable conditions for growth, mainly good lighting, moisture and warmth. The absence of one or other of these two essentials means no regeneration.

In our logging practice we have failed to provide these two conditions for the species that we want to repopulate the areas that we cut. Indeed, speaking generally, we have created a condition favorable for the regeneration of the species that we don't want while at the same time we have made conditions almost impossible for the successful regeneration of those species that we prize most highly. If we have had any successes in some places these have been largely accidental.

The main reason for our failure is the simple fact that logging destroys the seedbed, particularly when we clear cut. The cleaner we cut, in general, the poorer will be the seedbed that we leave. Thus we destroy one of the two essentials for all species that reproduce by seed alone. For those that reproduce from living roots we have set up almost perfect conditions. We won't therefore, have many new seedlings in the next crop. We must depend then on whatever conifer advance growth survives the logging and on other growth that arises from living roots of trees and shrubs that can reproduce in that way, such as poplar, white birch, willow, maple, hazel, raspberry and others.

The feature to be noticed in this renewal of the forest is that, insofar as conifer reproduction is concerned, we are getting mainly advance growth and that that growth is mainly white spruce and balsam. Jack pine doesn't produce advance growth. It is too intolerant of shade and, moreover, the shedding of its seed requires very special conditions. Black spruce doesn't produce an appreciable amount of advance growth either. It is more tolerant of shade than jack pine, but less tolerant than white spruce or balsam fir and it releases its seed from the cones very sparingly, retaining most of it for years. The black 
spruce, however, has the habit of producing new growth by layering, that is, from rooted branches. There is then, opportunity for an admixture of black spruce in the new crop, but little opportunity for any jack pine.

Is it not clear, then, that our logging is transforming a once valuable coniferous forest into one of less valuable hardwoods. From the evidence available to us there is a very considerable area of cut-over land, particularly of the better quality sites, that is not reproducing satisfactorily either as to species or quantity. The extent of that land is increasing annually. It will continue to increase until the transformation from conifers to hardwoods is completeunless we give some help to the conifers.

Three methods of securing the regeneration that we desire are available to us.

1. We can alter our cutting practice so that the two essentials for the regeneration of the species that we desire are created while at the same time conditions for the renewal of the species that we do not wish remain unfavorable. Unfortunately no one knows at present how to do this for our commercially important conifers. Little progress has been made in the last fifty years in developing methods of logging that will ensure their adequate regeneration. Thus we shall have to await the findings of a long time research program before this method can be adopted.

2. We can at the time of cutting, or before or after cutting, do some cultural work that will make the ground conditions more favorable for tree species to seed up the area. We are still not very sure of the kind of regeneration that we will get, or whether we will get enough to justify the expenditures, although there is evidence, that for some species, jack pine, for example, the method may be successful. There is some evidence also, that it may prove successful for spruce. At present a number of agencies are investigating the possibilities. With this method we may be able to assist in the regeneration of the species that we desire by sowing their seed. Further research work is necessary, however, before we can adopt this method.

3. We can plant the species that we want on the areas that are not reproducing satisfactorily. This appears to be the one sure method of getting the desired results. All that we have to know is the species to plant and how to plant it. It will not be necessary to plant all of the cut-over areas, nor will it be necessary to plant the whole area of even one cutover, thus in the long run, in addition to being the surest method it may also be the least costly.

In conclusion may I say that I believe it to be of very great importance to every one of us that we maintain the valuable commercial conifers in our forest. Logging is not doing that for us. Protecting the forest from burning is not doing it either. Something more than cutting and protecting has to be done. We have to give assistance where it is most needed and that is on the best growing sites in the land. There we have to plant a tree - a tree that we may harvest in the future - a tree that will keep us in the paper producing business. 